\title{
Aspectos que influenciam a gestante na escolha do tipo de parto
}

\author{
Aspects that influence the pregnant woman in choosing the type of birth
}

Aspectos que influyen la mujer embarazada en la elección del tipo de parto

Jaqueline Michele Lamb*, Rossano Sartori Dal Molin.

\begin{abstract}
RESUMO
Objetivo: Descrever quais os principais fatores que influenciam a gestante na escolha do tipo de parto e identificar o papel do enfermeiro no auxílio dessa escolha. Métodos: Foi realizada uma revisão integrativa da literatura, nas bases de dados Scientific Electronic Library Online (SCIELO) e Biblioteca Virtual em Saúde (BVS), através dos descritores em ciências da saúde (DeCS): parto normal, cesárea, tomada de decisões, preferência do paciente e papel do profissional de enfermagem. Foram incluídos artigos disponíveis na íntegra, que abordaram a temática do estudo, publicados nos últimos dez anos e em língua portuguesa. Resultados: A amostra foi composta por 15 artigos, os quais evidenciaram que o principal fator que influencia a gestante na escolha pelo parto vaginal, é a melhor e mais rápida recuperação no pós-parto, já para a realização da cesárea o fator que mais citado é o medo da dor do parto vaginal. Considerações finais: Percebe-se que a autonomia da gestante na escolha do tipo de parto, está muito relacionada a disponibilidade de informações durante o pré-natal, nesse contexto o enfermeiro apresenta um papel fundamental, sendo um importante ator no processo educativo das gestantes, devendo ampliar a sua atuação e ter uma participação mais ativa no pré-natal.
\end{abstract}

Palavras-chave: Parto normal, Cesárea, Tomada de decisões, Preferência do paciente.

\begin{abstract}
Objective: To describe which main factors that influence the pregnant in choosing the type of delivery and the nurse's role in the assistance of this choice. Methods: It was realized an integrative revision of the literature, in data bases of Scientific Electronic Library Online (SCIELO), and Biblioteca Virtual em Saúde (BVS), through the descriptors in health sciences (DeCS): vaginal delivery, cesarean section, decision-making, patient's preference and role of nursing professional. It was included full available article, that approach this study's theme, published in the last ten years and in portuguese language. Results: A sample of 15 article was composed, which evidenced that the main factor that influences the choose by the pregnant for the vaginal birth is the best and quickest postpartum recovery, as for the cesarean section the most cited factor was the of the pain of vaginal birth. Final considerations: It is noticed that the autonomy of the pregnant woman in the choice of birth is very related to the available informationts through the prenatal care, in this context the nurse represents a fundamental role, being an important actor in the educational process of pregnant woman, having to enlarge your action and have an active participation on prenatal.
\end{abstract}

Keywords: Natural childbirth, Cesarean, Decision making, Patient preference.

\section{RESUMEN}

Objetivo: Describir los principales factores que influyen en la gestante a la hora de elegir el tipo de parto e identificar el papel de los enfermeros para ayudar a tomar esta decisión. Métodos: Se realizó una revisión integradora de la literatura en las bases de datos de la Biblioteca Electrónica Científica en Línea (SCIELO) y Biblioteca Virtual en Salud (BVS), utilizando los descriptores de ciencias de la salud (DeCS): parto normal, cesárea, toma de decisiones, preferencia del paciente y rol de la el profesional de enfermería. Se incluyeron artículos disponibles en su totalidad, que abordaron el tema del estudio, publicados en los últimos diez años y en portugués. Resultados: La muestra estuvo conformada por 15 artículos, los cuales mostraron que el principal factor que influye en la gestante a la hora de elegir el parto vaginal es la mejor y más rápida recuperación en el posparto, para la realización de la cesárea, el factor más mencionado es el miedo al dolor del parto vaginal. Consideraciones finales: Se advierte que la autonomía de la gestante en la elección del tipo de parto está íntimamente relacionada con la disponibilidad de información durante la atención prenatal, en este contexto, los enfermeros juegan un papel fundamental, siendo un actor importante en el proceso educativo de la gestante, y deben ampliar su desempeño y tener una participación más activa en la atención prenatal.

Palabras clave: Parto normal, Césarienne, Toma de decisiones, Prioridad del paciente.

${ }^{1}$ Centro Universitário FSG, Caxias do Sul - RS. *E-mail: jaqueline_lamb@hotmail.com

SUBMETIDO EM: 11/2021

ACEITO EM: 11/2021

PUBLICADO EM: 11/2021 


\section{INTRODUÇÃO}

As práticas de assistência ao parto passaram por grandes mudanças no decorrer dos anos, configurandose conforme as características da sociedade de cada época. Por muito tempo era considerado uma prática comum o parto domiciliar e não intervencionista, entretanto, no decorrer do século $\mathrm{XX}$, o ato do parto vem sendo transferido para o ambiente hospitalar. Essas modificações no processo de parturição, com os avanços tecnológicos e científicos da obstetrícia e o nascimento em ambiente hospitalar, trouxeram muitos benefícios para a assistência à gestante, principalmente no que diz respeito ao parto de alto risco, resultando na melhoria dos indicadores de morbimortalidade materna e neonatal. Porém, também vem expondo as gestantes a muitos procedimentos e intervenções, que por muitas vezes são desnecessários (RISCADO LC, et al., 2016; MINISTÉRIO DA SAÚDE, 2017).

A Organização Mundial de Saúde (2015), considera que a taxa ideal de partos cesáreos seja entre 10\% e $15 \%$ do total de partos realizados em um serviço de saúde. Entretanto, as cesáreas vêm se tornando cada vez mais frequentes, e os índices no Brasil vão muito além do considerado adequado, visto que, resultados de um estudo coordenado pela Fiocruz, revelaram que 52\% dos nascimentos no país são por cesarianas, com concentração ainda maior na rede privada. Não se tem uma justificativa clínica para um percentual tão elevado dessas cirurgias, mas entende-se que essas taxas estão relacionadas com algumas situações, como a preferência da gestante, o conhecimento da mesma sobre o assunto e a influência dos profissionais de saúde que prestam assistência a ela (LEAL MC, et al., 2014).

A escolha da mulher pelo tipo de parto envolve diversos fatores, porém está fortemente relacionada com a qualidade da assistência obstétrica e o conhecimento da mesma sobre o assunto, a partir das informações repassadas pelos profissionais da saúde. Diante disso, percebe-se a importância da qualificação da atenção à gestante, para que essas sejam devidamente orientadas e recebam o conhecimento necessário para tomar decisões, assim promovendo a sua autonomia e o direito de livre escolha da via de parto, considerando as implicações para a sua saúde e a do bebê (MINISTÉRIO DA SAÚDE, 2014; FEITOSA RMM, et al., 2017).

$\mathrm{Na}$ qualificação da assistência prestada à gestante, o enfermeiro exerce um papel fundamental desde a atenção primária, através das orientações e esclarecimentos prestados nas consultas de pré-natal, sendo um dos responsáveis por promover a educação em saúde necessária para que a gestante assuma o protagonismo do processo de nascimento (DARÓs DZ, et al., 2010).

De acordo com Carvalho SS e Cerqueira RFN (2020), apesar de que em teoria são preconizadas as medidas de parto não cirúrgicas, nota-se que na prática as condutas intervencionistas são cada vez mais empregadas, mesmo sem uma indicação específica. Diante disso, o objetivo do presente estudo foi descrever quais os principais fatores que influenciam a gestante na escolha do tipo de parto e identificar o papel do enfermeiro no auxílio dessa escolha.

\section{MÉTODOS}

A abordagem do presente estudo constituiu-se em uma revisão integrativa da literatura, com caráter analítico, realizado através da análise da literatura disponível sobre o tema abordado, sendo norteado pela seguinte questão: Quais são os principais fatores que influenciam a gestante na escolha pelo tipo de parto?

As buscas ocorreram nas bases de dados Scientific Electronic Library Online (SCIELO) e Biblioteca Virtual em Saúde (BVS), através dos Descritores em Ciências da Saúde (DeCS): parto normal, cesárea, tomada de decisões, preferência do paciente e papel do profissional de enfermagem, os quais foram associados com os operadores booleanos "AND" e "OR".

Os artigos foram selecionados com base nos seguintes critérios de inclusão: abordam a temática do estudo, disponíveis de forma online e gratuita, publicados dentro dos últimos dez anos e disponíveis no idioma português. Foram excluídos da pesquisa artigos não disponibilizados eletronicamente em texto completo, que não respondem à questão norteadora e artigos de revisão.

A avaliação dos dados se deu por meio da leitura dos resumos dos artigos, determinando quais responderam à questão norteadora da pesquisa. Após, os artigos selecionados foram lidos na íntegra, de forma criteriosa, e as principais informações coletadas foram registradas em um instrumento de coleta 
elaborado durante o projeto de pesquisa. Esse instrumento foi preenchido com os dados de identificação dos artigos, objetivos, resultados e conclusão, assim facilitando a organização e escolha dos conteúdos mais relevantes. Os dados extraídos foram analisados e sintetizados, comparando-se as informações para compreender o conteúdo, encontrar as respostas da questão norteadora, e realizar a construção da discussão do estudo.

Por se tratar de uma revisão de literatura, que faz uso de dados de domínio público, não foi necessário submeter a pesquisa ao Comitê de ética em Pesquisa. Entretanto, todos os preceitos éticos serão respeitados, no que se refere a legitimidade das informações e a garantia da autoria dos artigos pesquisados.

\section{RESULTADOS}

Durante as buscas nas bases de dados, foram encontrados 4.382 artigos relacionados aos descritores parto normal, cesárea, tomada de decisões, preferência do paciente e papel do profissional de enfermagem. Em seguida, foram aplicados os critérios de inclusão, sendo selecionados apenas os artigos publicados dentro dos últimos dez anos, disponíveis na língua portuguesa e de forma online e gratuita, chegando em um total de 140 artigos. Após a leitura do título e/ou resumo dos artigos restantes, foram excluídos ainda, artigos de revisão, duplicados nas bases de dados e aqueles que não respondiam à questão norteadora da pesquisa. Os 22 artigos restantes foram lidos na íntegra, onde 7 fugiram da temática da pesquisa. Assim, a amostra foi composta por 15 estudos, sendo 4 encontrados no Scielo e 11 na BVS, conforme mostra a Figura 1.

Figura 1 - Fluxograma de seleção dos artigos para Revisão Integrativa.

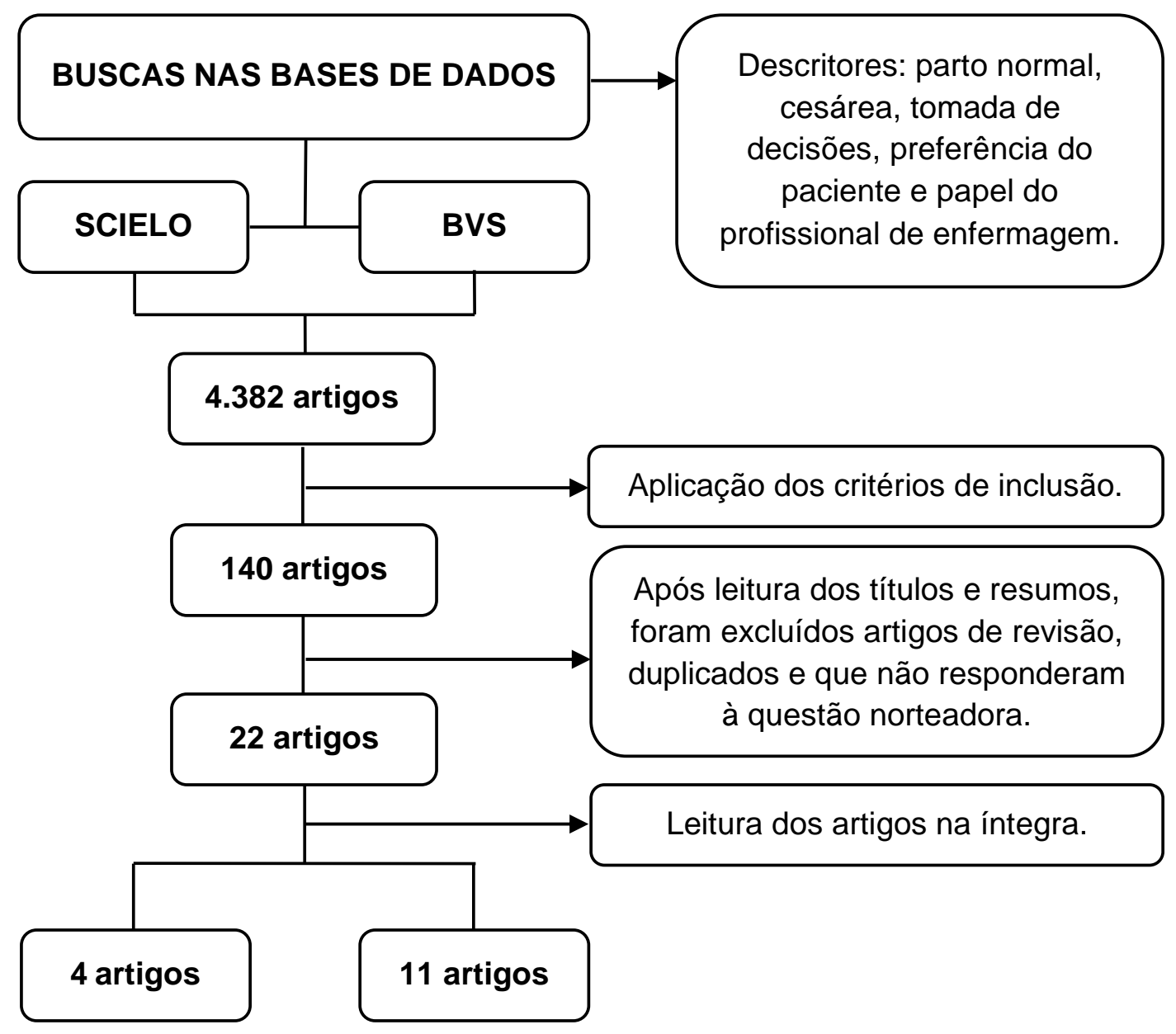

Fonte: Lamb JM e Molin RSD, 2021.

Os dados do Quadro 1, apresentam os 15 artigos científicos, selecionados para compor o presente estudo, que corresponderam aos critérios de inclusão e exclusão previamente estabelecida. 
Quadro 1 - Apresentação da síntese das características dos estudos incluídos nesta revisão integrativa.

\begin{tabular}{|c|c|c|c|c|c|}
\hline $\begin{array}{c}\text { Base da } \\
\text { dados }\end{array}$ & Título & Autores (ano) & Objetivo & Resultados/Discussão & Conclusão \\
\hline BVS & $\begin{array}{l}\text { Razões maternas da } \\
\text { preferência inicial pelo } \\
\text { tipo de parto em um } \\
\text { município do nordeste } \\
\text { brasileiro }\end{array}$ & $\begin{array}{c}\text { Silva DES, et al. } \\
(2020) .\end{array}$ & $\begin{array}{l}\text { Identificar as razões } \\
\text { maternas da preferência } \\
\text { pelo tipo de parto no início } \\
\text { da gravidez. }\end{array}$ & $\begin{array}{l}73,3 \% \text { das mulheres desejaram parto vaginal } \\
\text { no início da gravidez, pela melhor } \\
\text { recuperação, desejo pessoal e experiência } \\
\text { positiva. Já a escolha da cesariana, é pelo } \\
\text { medo da dor do parto vaginal. No final da } \\
\text { gestação, houve um aumento na decisão } \\
\text { materna e/ou do profissional pela cirurgia. }\end{array}$ & $\begin{array}{l}\text { Recomenda-se que os profissionais } \\
\text { responsáveis pelo pré-natal possam } \\
\text { estabelecer uma melhor comunicação } \\
\text { com as gestantes, discutindo sobre } \\
\text { ambas vias de parto e desmistificando } \\
\text { mitos para uma escolha consciente e } \\
\text { segura. }\end{array}$ \\
\hline BVS & $\begin{array}{c}\text { Percepções e } \\
\text { expectativas de } \\
\text { gestantes sobre o tipo } \\
\text { de parto }\end{array}$ & $\begin{array}{l}\text { Arik RM, et al. } \\
\text { (2019). }\end{array}$ & $\begin{array}{l}\text { Apreender as percepções } \\
\text { e expectativas de } \\
\text { gestantes sobre o tipo de } \\
\text { parto. }\end{array}$ & $\begin{array}{l}\text { Conforme os discursos, os aspectos que } \\
\text { foram considerados associaram-se em quatro } \\
\text { temas: vantagens do parto vaginal sobre a } \\
\text { cesariana; Medo e imprevisibilidade do parto } \\
\text { vaginal; Importância do médico na definição } \\
\text { do tipo de parto; Influência da família e } \\
\text { amigos na escolha do tipo de parto. }\end{array}$ & $\begin{array}{l}\text { Para as gestantes, o parto vaginal } \\
\text { apresenta benefício em comparação à } \\
\text { operação cesariana. Mas, o medo da dor } \\
\text { e do inesperado, opiniões médicas, e de } \\
\text { familiares influenciam fortemente a } \\
\text { opção pela operação cesariana. }\end{array}$ \\
\hline BVS & $\begin{array}{l}\text { Da decisão à vivência } \\
\text { da cesariana: a } \\
\text { perspectiva da mulher }\end{array}$ & $\begin{array}{l}\text { Paiva ACPC, et } \\
\text { al. (2019). }\end{array}$ & $\begin{array}{l}\text { Descrever o processo de } \\
\text { decisão da mulher } \\
\text { primípara pela via de } \\
\text { nascimento, } \\
\text { compreendendo a vivência } \\
\text { da cesariana por elas. }\end{array}$ & $\begin{array}{l}\text { Percebeu-se que a maioria das mulheres já } \\
\text { chega ao consultório decidida sobre a via de } \\
\text { nascimento, mas, nem todas conseguiram } \\
\text { prosseguir com a escolha inicial. A vivência } \\
\text { da cesariana foi positiva, mesmo para as } \\
\text { mulheres que tinham como primeira opção o } \\
\text { parto normal. }\end{array}$ & $\begin{array}{l}\text { Ressalta-se a importância de a equipe de } \\
\text { saúde atuar efetivamente no } \\
\text { compartilhamento de informações e } \\
\text { construção do vínculo, desde o pré-natal } \\
\text { até o puerpério. }\end{array}$ \\
\hline BVS & $\begin{array}{l}\text { Autonomia da } \\
\text { gestante na escolha } \\
\text { do tipo de parto }\end{array}$ & $\begin{array}{c}\text { Silva MMJ, et al. } \\
\text { (2019). }\end{array}$ & $\begin{array}{l}\text { Identificar a preferência da } \\
\text { gestante primigesta } \\
\text { quanto à via de parto e } \\
\text { conhecer os fatores que } \\
\text { influenciam a sua tomada } \\
\text { de decisão nessa escolha. }\end{array}$ & $\begin{array}{l}\text { Predominou a escolha pelo parto vaginal, a } \\
\text { presença de expectativas positivas em } \\
\text { relação a via escolhida e a não influência de } \\
\text { terceiros sobre a decisão. }\end{array}$ & $\begin{array}{l}\text { A escolha da mulher pela via de parto } \\
\text { está se transformando em uma } \\
\text { preferência e não apenas em uma } \\
\text { indicação profissional, o que ressalta a } \\
\text { importância da educação em saúde no } \\
\text { pré-natal. }\end{array}$ \\
\hline BVS & $\begin{array}{l}\text { Aspectos que } \\
\text { influenciam a tomada } \\
\text { de decisão da mulher } \\
\text { sobre o tipo de parto }\end{array}$ & $\begin{array}{l}\text { Martins APC, et } \\
\quad \text { al. (2018). }\end{array}$ & $\begin{array}{l}\text { Conhecer os aspectos que } \\
\text { influenciam na tomada de } \\
\text { decisão sobre o tipo de } \\
\text { parto, por gestantes no } \\
\text { terceiro trimestre de } \\
\text { gestação. }\end{array}$ & $\begin{array}{l}\text { O parto vaginal foi apontado como a via de } \\
\text { preferência entre as gestantes. As } \\
\text { experiências vivenciadas por pessoas } \\
\text { próximas e pela própria gestante, e a } \\
\text { assistência pré-natal recebida foram os } \\
\text { aspectos influenciadores na decisão da } \\
\text { mulher. }\end{array}$ & $\begin{array}{l}\text { A escolha do tipo de parto não foi } \\
\text { influenciada por um aspecto apenas, } \\
\text { mas por uma série de fatores } \\
\text { indissociáveis, que separadamente, } \\
\text { talvez não fossem capazes de influenciar } \\
\text { a decisão. }\end{array}$ \\
\hline
\end{tabular}




\begin{tabular}{|c|c|c|c|c|c|}
\hline $\begin{array}{l}\text { Base da } \\
\text { dados }\end{array}$ & Título & Autores (ano) & Objetivo & Resultados/Discussão & Conclusão \\
\hline BVS & $\begin{array}{l}\text { Parto normal ou } \\
\text { cesárea na } \\
\text { adolescência: de } \\
\text { quem é a decisão? }\end{array}$ & $\begin{array}{c}\text { Matos GC, et al. } \\
(2018) .\end{array}$ & $\begin{array}{l}\text { Averiguar a participação } \\
\text { da mulher na tomada de } \\
\text { decisão durante os partos } \\
\text { recorrentes r na } \\
\text { adolescência. }\end{array}$ & $\begin{array}{l}\text { Mulheres que não possuem conhecimento a } \\
\text { respeito do processo de parturição transferem } \\
\text { a decisão sobre o tipo de parto ao médico. Já, } \\
\text { quando obtêm conhecimento, demonstram } \\
\text { voz ativa na tomada de decisão. }\end{array}$ & $\begin{array}{l}\text { O pilar da tomada de decisão em relação } \\
\text { ao tipo de parto está ligado ao } \\
\text { fornecimento de informações à mulher. }\end{array}$ \\
\hline SCIELO & $\begin{array}{l}\text { Via de parto preferida } \\
\text { por puérperas e suas } \\
\text { motivações }\end{array}$ & $\begin{array}{c}\text { Kottwitz F, et al. } \\
(2018) .\end{array}$ & $\begin{array}{l}\text { Conhecer a via de parto } \\
\text { preferida pelas puérperas } \\
\text { e suas motivações. }\end{array}$ & $\begin{array}{l}77,6 \% \text { das mulheres preferiram o parto } \\
\text { vaginal, devido a melhor recuperação; } 20,5 \% \\
\text { acreditaram ter participado da decisão sobre } \\
\text { o tipo de parto. Houve associação entre } \\
\text { experiência prévia com a via de parto } \\
\text { preferida. }\end{array}$ & $\begin{array}{l}\text { As mulheres não demonstraram } \\
\text { conhecimento adequado sobre os riscos } \\
\text { e benefícios dos tipos de parto e, por } \\
\text { isso, não estão empoderadas para } \\
\text { exercer sua autonomia nessa decisão. }\end{array}$ \\
\hline BVS & $\begin{array}{l}\text { Cada parto é uma } \\
\text { história: processo de } \\
\text { escolha da via de } \\
\text { parto }\end{array}$ & $\begin{array}{l}\text { Oliveira VJ e } \\
\text { Penna CMM } \\
\text { (2018). }\end{array}$ & $\begin{array}{l}\text { Analisar os discursos } \\
\text { sobre escolha da via de } \\
\text { parto na perspectiva de } \\
\text { mulheres e profissionais } \\
\text { de saúde de uma rede } \\
\text { pública. }\end{array}$ & $\begin{array}{l}\text { A escolha da via de parto está relacionada } \\
\text { com fatores culturais e sociais e a um modelo } \\
\text { de assistência ao parto intervencionista. A } \\
\text { cesárea é percebida como mais prática e } \\
\text { confiável. Os discursos revelam que a } \\
\text { decisão do tipo de parto tem uma } \\
\text { dependência excessiva da determinação do } \\
\text { médico. }\end{array}$ & $\begin{array}{l}\text { Na perspectiva das parturientes o tipo de } \\
\text { parto é determinado pelo médico e as } \\
\text { mulheres não são proativas. A atuaccão } \\
\text { do enfermeiro é tímida, embora sua } \\
\text { presenca seia fundamental para o } \\
\text { estímulo ao parto fisiológico e promoçãa } \\
\text { da autonomia das mulheres. }\end{array}$ \\
\hline BVS & $\begin{array}{l}\text { Percepção de } \\
\text { gestantes e puérperas } \\
\text { primíparas sobre a } \\
\text { maternidade }\end{array}$ & $\begin{array}{l}\text { Demarchi RF, et } \\
\text { al. (2017). }\end{array}$ & $\begin{array}{l}\text { Investigar a percepção de } \\
\text { gestantes e puérperas } \\
\text { primíparas } \\
\text { sobre maternidade. }\end{array}$ & $\begin{array}{l}\text { Com a maternidade, a mulher passa por } \\
\text { transformações e reorganização da dinâmica } \\
\text { familiar. As consultas de pré-natal ajudam no } \\
\text { enfrentamento da maternidade, sendo o } \\
\text { enfermeiro um dos responsáveis pelo } \\
\text { sucesso delas. }\end{array}$ & $\begin{array}{l}\text { As consultas de pré-natal mostram-se } \\
\text { favoráveis por serem momentos de } \\
\text { solução de dúvidas e de acolhimento, } \\
\text { principalmente se esse atendimento for } \\
\text { multidisciplinar. }\end{array}$ \\
\hline BVS & $\begin{array}{c}\text { Preferência e fatores } \\
\text { associados ao tipo de } \\
\text { parto entre puérperas } \\
\text { de uma mater-nidade } \\
\text { pública }\end{array}$ & $\begin{array}{l}\text { Vale LD, et al. } \\
\quad(2015)\end{array}$ & $\begin{array}{lr}\text { Identificar os } & \text { fatores } \\
\text { obstétricos } & e \\
\text { socioeconômicos } & \text { que } \\
\text { influenciam a preferência } \\
\text { pelo tipo de parto. }\end{array}$ & $\begin{array}{l}\text { A preferência pelo parto vaginal foi citada por } \\
58 \% \text { das mulheres. As principais justificativas } \\
\text { foram a rápida recuperação e experiência } \\
\text { negativa na cesariana. Também, evidenciou- } \\
\text { se relação com experiência anterior desse } \\
\text { tipo de parto e orientação prévia. }\end{array}$ & $\begin{array}{l}\text { A cesariana foi a via de parto mais } \\
\text { prevalente, mas, o vaginal foi o parto de } \\
\text { preferência da maioria das puérperas. } \\
\text { Evidenciando necessidade de } \\
\text { transformação no modelo de atenção à } \\
\text { gestação e ao parto. }\end{array}$ \\
\hline
\end{tabular}




\begin{tabular}{|c|c|c|c|c|c|}
\hline $\begin{array}{c}\text { Base da } \\
\text { dados }\end{array}$ & Título & Autores (ano) & Objetivo & Resultados/Discussão & Conclusão \\
\hline SCIELO & $\begin{array}{l}\text { Escolha do tipo de } \\
\text { parto: fatores } \\
\text { relatados por } \\
\text { puérperas }\end{array}$ & $\begin{array}{l}\text { Nascimento } \\
\text { RRP, et al. } \\
\text { (2015). }\end{array}$ & $\begin{array}{l}\text { Conhecer os fatores } \\
\text { relatados por puérperas } \\
\text { que concorreram na } \\
\text { escolha do tipo de parto. }\end{array}$ & $\begin{array}{l}\text { A maioria das mulheres entrevistadas } \\
\text { manifestou preferência pelo parto normal } \\
\text { devido à recuperação rápida, menor dor e } \\
\text { sofrimento. }\end{array}$ & $\begin{array}{l}\text { Concorreram na escolha do tipo de parto: } \\
\text { influência da família, experiências } \\
\text { prévias, interação com profissional e } \\
\text { informações via internet, reforçando a } \\
\text { importância da educação em saúde } \\
\text { desde o pré-natal. }\end{array}$ \\
\hline SCIELO & $\begin{array}{l}\text { Processo de decisão } \\
\text { pelo tipo de parto no } \\
\text { Brasil: da preferência } \\
\text { inicial das mulheres à } \\
\text { via de parto final }\end{array}$ & $\begin{array}{l}\text { Domingues } \\
\text { RMSM, et al. } \\
\text { (2014). }\end{array}$ & $\begin{array}{l}\text { Descrever os fatores para } \\
\text { a preferência pelo tipo de } \\
\text { parto no início da gestação } \\
\text { e reconstruir o processo de } \\
\text { decisão pelo tipo de parto } \\
\text { no Brasil. }\end{array}$ & $\begin{array}{l}\text { O principal motivo para a escolha do parto } \\
\text { vaginal foi a melhor recuperação e para a } \\
\text { cesariana o medo da dor do parto vaginal. } \\
\text { Mulheres do setor privado apresentaram } \\
87,5 \% \text { de cesariana, com aumento da decisão } \\
\text { pelo parto cesáreo no final da gestação. }\end{array}$ & $\begin{array}{l}\text { O grande desafio que persiste é o de } \\
\text { transformar recomendações em práticas, } \\
\text { com adoção, nos serviços públicos e } \\
\text { privados, de protocolos assistenciais } \\
\text { baseados em evidências científicas. }\end{array}$ \\
\hline BVS & $\begin{array}{l}\text { Parto normal ou } \\
\text { cesárea? A Decisão } \\
\text { na voz das mulheres }\end{array}$ & $\begin{array}{l}\text { Freire NC, et al. } \\
\qquad(2011) .\end{array}$ & $\begin{array}{l}\text { Descrever o processo de } \\
\text { tomada de decisão das } \\
\text { mulheres sobre a via de } \\
\text { parto e identificar os } \\
\text { fatores associados à } \\
\text { tomada de decisão. }\end{array}$ & $\begin{array}{l}\text { Processo de decisão sobre a via de parto } \\
\text { centrado no saber médico, supostamente } \\
\text { indiscutível, reafirmando a hegemonia do } \\
\text { conhecimento e do poder médico sobre o } \\
\text { corpo das mulheres. }\end{array}$ & $\begin{array}{l}\text { Há necessidade de melhoria da } \\
\text { qualidade do pré-natal, preparando a } \\
\text { mulher física e emocionalmente para o } \\
\text { parto natural, fornecendo os recursos } \\
\text { que possibilitem a tomada de decisão } \\
\text { consciente. }\end{array}$ \\
\hline BVS & $\begin{array}{l}\text { Parto normal X Parto } \\
\text { cesáreo: escolha ou } \\
\text { necessidade? }\end{array}$ & $\begin{array}{c}\text { Silva AKB, et al. } \\
(2011) .\end{array}$ & $\begin{array}{l}\text { Analisar aspectos } \\
\text { relacionados à preferência } \\
\text { na via de parto entre } \\
\text { gestantes do município de } \\
\text { Arcoverde. }\end{array}$ & $\begin{array}{l}\text { Das gestantes estudadas, } 63 \% \text { preferiam } \\
\text { o parto vaginal e a maioria relatou ser devido } \\
\text { à recuperação mais rápida; } 37 \% \text { relataram a } \\
\text { preferência pelo parto cirúrgico devido à } \\
\text { oportunidade de laqueadura. }\end{array}$ & $\begin{array}{l}\text { Mesmo prevalecendo a escolha } \\
\text { pelo parto normal, a taxa de preferência } \\
\text { por cesariana ainda foi alta. } \\
\text { Muitas gestantes não } \\
\text { informação acerca da importância } \\
\text { do parto normal. }\end{array}$ \\
\hline SCIELO & $\begin{array}{l}\text { Representações } \\
\text { sociais e decisões das } \\
\text { gestantes sobre } \\
\text { parturição: } \\
\text { protagonismo das } \\
\text { mulheres }\end{array}$ & $\begin{array}{l}\text { Pereira RR, et al. } \\
(2011) .\end{array}$ & $\begin{array}{l}\text { Compreender, a partir das } \\
\text { representações sociais } \\
\text { femininas, o protagonismo } \\
\text { da mulher na decisão } \\
\text { sobre a parturição. }\end{array}$ & $\begin{array}{l}\text { A representação social da mulher no } \\
\text { processo da parturição, é simbolizado por } \\
\text { conflitos de sentimentos, dúvidas e } \\
\text { apreensões originadas principalmente pelo } \\
\text { medo do sofrimento imposto pela dor. }\end{array}$ & $\begin{array}{l}\text { A mulher apresenta uma autonomia } \\
\text { limitada que compromete seu } \\
\text { protagonismo no processo da parturição. } \\
\text { Sua opinião sobre a via de parto torna-se } \\
\text { manipulável pelo medo do } \\
\text { desconhecido. }\end{array}$ \\
\hline
\end{tabular}

Fonte: Lamb JM e Molin RSD, 2021. 
Os dados do Quadro 2, trazem o tamanho da amostra e uma síntese dos principais fatores associados à escolha da via de parto dos artigos científicos que compõem esta revisão.

Quadro 2 - Apresentação da amostra e dos fatores associados à escolha da via de parto mais relatados.

\begin{tabular}{|c|c|c|}
\hline Autores & Amostra & Fatores e Influências \\
\hline $\begin{array}{l}\text { Silva DES, et al. } \\
\qquad(2020)\end{array}$ & 655 puérperas & $\begin{array}{l}\text { PN: Melhor recuperação no pós-parto, desejo pessoal e } \\
\text { experiência positiva; } \\
\text { PC: medo da dor do parto vaginal e o desejo pessoal. }\end{array}$ \\
\hline $\begin{array}{l}\text { Arik RM, et al. } \\
\qquad(2019) \text {. }\end{array}$ & 15 gestantes & $\begin{array}{l}\text { PN: rápida recuperação, menor risco de infecção, respeito pelo } \\
\text { tempo do bebê; } \\
\text { PC: medo da dor e imprevisibilidade do } \mathrm{PN} \text {; }\end{array}$ \\
\hline $\begin{array}{l}\text { Paiva ACPC, et al. } \\
\text { (2019). }\end{array}$ & 10 puérperas & $\begin{array}{l}\text { PC: medo da dor, comodidade da previsão e controle do momento } \\
\text { do nascimento; }\end{array}$ \\
\hline $\begin{array}{l}\text { Silva MMJ, et al. } \\
(2019) .\end{array}$ & 35 gestantes & $\begin{array}{l}\text { PN: rápida recuperação, pelo parto ser natural e dor única; } \\
\text { PC: indicação clínica e medo da dor; }\end{array}$ \\
\hline $\begin{array}{l}\text { Martins APC, et al. } \\
\qquad(2018) .\end{array}$ & 15 gestantes & $\begin{array}{l}\text { PN: recuperação rápida e fácil, pelo parto ser natural e fisiológico; } \\
\text { PC: medo e entendimento que a dor do parto vaginal é um } \\
\text { sofrimento desnecessário; }\end{array}$ \\
\hline $\begin{array}{l}\text { Matos GC, et al. } \\
(2018)\end{array}$ & 30 mulheres & Influências: experiências prévias e informações recebidas; \\
\hline $\begin{array}{l}\text { Kottwitz F, et al. } \\
\text { (2018). }\end{array}$ & 361 puérperas & $\begin{array}{l}\text { PN: melhor recuperação, mais seguro; } \\
\text { PC: desejo de não sentir dor e experiência prévia positiva; }\end{array}$ \\
\hline $\begin{array}{l}\text { Oliveira VJ e } \\
\text { Penna CMM } \\
(2018)\end{array}$ & $\begin{array}{l}36 \text { mulheres, } \\
10 \text { enfermeiras } \\
\text { e } 14 \text { médicos }\end{array}$ & $\begin{array}{l}\text { PN: recuperação mais rápida; } \\
\text { PC: medo da dor; }\end{array}$ \\
\hline $\begin{array}{l}\text { Demarchi RF, et al. } \\
\text { (2017). }\end{array}$ & 11 mulheres & e r l \\
\hline $\begin{array}{l}\text { Vale LD, et al. } \\
\qquad(2015)\end{array}$ & 233 puérperas & $\begin{array}{l}\text { PN: recuperação mais rápida e experiência negativa no pós-parto } \\
\text { de cesárea; } \\
\text { PC: medo da dor, insegurança na assistência local, experiência } \\
\text { positiva com cesárea e negativa com parto normal e laqueadura } \\
\text { tubária. }\end{array}$ \\
\hline $\begin{array}{l}\text { Nascimento RRP, } \\
\text { et al. (2015). }\end{array}$ & 25 puérperas & $\begin{array}{l}\text { PN: recuperação mais rápida possibilitando os cuidados com bebê } \\
\text { sem restrições e por ser um processo natural; } \\
\text { PC: medo da dor; }\end{array}$ \\
\hline $\begin{array}{l}\text { Domingues RMSM, } \\
\text { et al. (2014). }\end{array}$ & $\begin{array}{c}23.940 \\
\text { puérperas }\end{array}$ & $\begin{array}{l}\text { PN: mais natural e fisiológico, recuperação mais rápida, } \\
\text { experiência anterior positiva; } \\
\text { PC: medo da dor, comodidade pela possibilidade de planejamento, } \\
\text { realização de laqueadura tubária, medo de não conseguir } \\
\text { atendimento; }\end{array}$ \\
\hline $\begin{array}{l}\text { Freire NC, et al. } \\
\quad(2011) \text {. }\end{array}$ & 12 mulheres & PC: medo da dor, preocupação em garantir o bem-estar do bebê; \\
\hline $\begin{array}{l}\text { Silva AKB, et al. } \\
(2011) .\end{array}$ & 71 gestantes & $\begin{array}{l}\text { PN: recuperação mais rápida e experiência anterior positiva; } \\
\text { PC: medo da dor e oportunidade para laqueadura; }\end{array}$ \\
\hline $\begin{array}{l}\text { Pereira RR, et al. } \\
(2011) .\end{array}$ & 45 gestantes & $\begin{array}{l}\text { Influências: medo, preocupações, vivências anteriores } \\
\text { desinformação. }\end{array}$ \\
\hline
\end{tabular}

Legenda: PN: Parto Normal; PC: Parto cesárea; * Este artigo trata da visão das mulheres quanto à atuação dos profissionais da saúde, não abordando fatores relacionas à escolha da via de parto.

Fonte: Lamb JM e Molin RSD, 2021.

\section{DISCUSSÃO}

A partir da análise dos estudos que compõem essa revisão, foram organizadas três categorias analíticas: "Da preferência inicial à via de parto final", "Fatores relacionados à escolha do tipo de parto" e "Papel do profissional enfermeiro". 


\section{Da preferência inicial à via de parto final}

Identificou-se que geralmente, a preferência inicial das mulheres é pelo parto vaginal, mas que o desejo materno vai apresentando alterações durante o decorrer do pré-natal, mostrando que os profissionais de saúde influenciam significativamente no desejo materno pelo tipo de parto durante esse acompanhamento. Visto que é percebido, aumento da indecisão no decorrer da gravidez e da preferência final pela cesariana, o que pode estar ligado com a falta de informações suficientes prestadas para essas gestantes. Isso mostra que os altos índices de partos cirúrgicos nem sempre estão relacionados ao desejo inicial ou final da mulher (SILVA DES, et al., 2020; ARIK RM, et al., 2019; VALE LD, et al., 2015).

Entretanto, se tratando do setor privado, o estudo de Domingues RMSM, et al. (2014), verifica uma proporção maior de mulheres com preferência inicial pela cesariana, número que quase dobrou no final da gestação. Das mulheres que desejavam esse tipo de parto, $96,5 \%$ o tiveram, em sua grande maioria sem relação com a ocorrência de intercorrências na gravidez. Se tratando da preferência pela cesariana, a menor taxa é em primíparas do setor público e a maior em multíparas com cesariana prévia do setor privado.

Outro ponto alarmante encontrado, é a falta de informações e orientações no pré-natal, onde dois estudos trazem altas porcentagens $(47,2$ e $51 \%)$ de relatos, das mulheres não terem recebido nenhuma orientação sobre o parto durante as consultas. Além disso, também foi identificado uma pesquisa onde $72 \%$ das mulheres não foram nem ao menos questionadas quanto a sua preferência em relação ao tipo de parto durante as consultas de pré-natal (VALE LD, et al., 2015; SILVA AKB, et al., 2011; KOTTWITZ F, et al., 2018).

Contrapondo-se à visão de outros autores, na pesquisa de Silva MMJ, et al. (2019), todas gestantes relataram não ter dúvidas e a maior parte recebeu informações quanto aos tipos de parto durante o pré-natal, sendo informadas que ambos tipos de parto são seguros e, quanto a decisão pela via de parto, $71,4 \%$ referiram não ter sofrido influências na escolha. Entretanto, o estudo teve uma amostra um pouco menor de participantes, com apenas 35 puérperas.

Um fator positivo encontrado, é de que o desejo inicial da gestante pelo tipo de parto favoreceu a realização do mesmo por esta via, mostrando que apesar das oscilações da escolha materna durante a gravidez, a preferência inicial é considerada pelos profissionais de saúde (SILVA DES, et al., 2020).

\section{Fatores relacionados à escolha do tipo de parto}

Se tratando dos fatores relacionados com a escolha do tipo de parto, a maior parte dos artigos trouxe resultados similares, tanto para justificar a preferência pelo parto vaginal, quanto para a cesariana.

No que diz respeito à preferência pelo parto vaginal, o fator que mais aparece nos estudos é a melhor e mais rápida recuperação no pós-parto, assim possibilitando a realização dos cuidados com o bebê sem tantas restrições, seguido pelo entendimento de que o parto vaginal é um processo natural e fisiológico. Outros fatores que também apareceram são a experiência prévia positiva, o parto ser mais seguro e com menor risco de infecção, a dor única e o respeito pelo tempo do bebê (SILVA DES, et al., 2020; ARIK RM, et al., 2019; SILVA MMJ, et al., 2019; MARTINS APC, et al., 2018; OLIVEIRA VJ e PENNA CMM, 2018; KOTTWITZ F, et al., 2018; VALE LD, et al., 2015; NASCIMENTO RRP, et al., 2015; DOMINGUES RMSM, et al., 2014; SILVA AKB, et al., 2011).

Silva DES, et al (2020), salienta que além da recuperação mais rápida, também são benefícios do parto vaginal, o favorecimento da descida do leite materno, menores riscos de infecção em relação à incisão cirúrgica da cesárea, liberdade de posição e alimentação durante o trabalho de parto, maior facilidade de amamentar no pós-parto imediato, além de contribuir com a participação do acompanhante.

Quanto à preferência pelo parto cesáreo, o principal fator citado é o medo da dor do parto vaginal, seguido pelo aproveitamento para realização de laqueadura tubária e pela comodidade em poder planejar e programar a data do nascimento. Os relatos das mulheres, demonstram a insegurança quanto a imprevisibilidade do parto normal e a assistência local e o desejo de não sentir dor (SILVA DES, et al., 2020; ARIK RM, et al., 2019; SILVA MMJ, et al., 2019; PAIVA ACPC, et al., 2019; MARTINS APC, et al., 2018; OLIVEIRA VJ e PENNA CMM, 2018; KOTTWITZ F, et al., 2018; VALE LD, et al., 2015; NASCIMENTO RRP, et al., 2015; DOMINGUES RMSM, et al., 2014; FREIRE NC, et al., 2011; SILVA AKB, et al., 2011). 
O medo da dor do parto vaginal é algo normal e compreensível, está muito relacionado a uma cultura que estereotipou a dor do parto e também a experiências prévias e relatos de parentes e conhecidas, com situações de partos dolorosos e desumanizados. Portanto, é necessário salientar e orientar as gestantes, de que a dor é realmente associada ao trabalho de parto, mas que não precisa necessariamente ser inteiramente ligada a sofrimento e que existem métodos para o alívio da dor (SILVA DES, et al., 2020).

As principais questões negativas encontradas, relacionadas a cesariana, são a recuperação mais demorada e a dor do pós-parto, o que provocam uma maior dependência dos familiares para as atividades rotineiras e maiores dificuldades no cuidado do bebê (ARIK RM, et al., 2019).

No estudo de Paiva ACPC, et al. (2019), para algumas primíparas, mesmo o desejo inicial sendo o parto vaginal, após o início das contrações elas acabaram optando pela cesárea, motivadas pela dor muito forte. Essa mudança da escolha durante o trabalho de parto está atrelada a crença de que a cesariana seja indolor e mais segura, e devido à falta de orientações prestadas a gestante sobre o trabalho de parto.

Essa falta de orientações claras sobre a progressão do parto vaginal e sobre as técnicas que propiciam um trabalho de parto seguro e mais confortável, além da falta de disponibilização de métodos não farmacológicos para o alívio da dor das gestantes, dificultam a manutenção da preferência pelo parto vaginal (ARIK RM, et al., 2019).

No que se refere às experiências prévias, tanto para o parto vaginal quanto a cesariana, percebe-se que se a experiência com o parto anterior foi positiva, passa a ser novamente a via de preferência da mulher, entretanto se for negativa, traz sentimentos de medo e preocupação, favorecendo a escolha contrária na próxima oportunidade. Notou-se ainda, que as mulheres que já tiveram parto normal dão preferência maior pela repetição da via de parto, e que a cultura deturpada de acreditar que uma vez cesariana, sempre cesariana, ainda é muito presente entre as mulheres (VALE LD, et al., 2015).

Se tratando das gestantes adolescentes o estudo de Matos GC, et al. (2018), aborda o fato de a adolescente primípara não ter voz ativa na decisão pela via de parto, principalmente pela falta de conhecimento das mesmas sobre o processo de parturição e do medo de ser julgada, somado ao entendimento de que o médico detém do conhecimento, fazendo com que elas acabem transferindo essa decisão para o profissional.

É importante salientar, que as altas taxas de cesariana em primíparas são consideradas um fator preocupante, pois conforme os estudos, existe uma alta taxa de repetição da via de parto prévia, indicando a possibilidade significativa de novas cesarianas futuras (VALE LD, et al., 2015).

Kottwitz F, et al. (2018) não encontrou associação significativa entre a escolaridade e preferência pelo parto, entretanto em sua análise ele trouxe duas possibilidades, o fato da maior escolaridade poder indicar maior informação e conhecimento acerca da gestação e parturição, assim aumentando a escolha pela via de parto vaginal, mas em contraponto, a maior instrução pode possibilitar o aumento do poder aquisitivo e da utilização dos serviços privados, os quais sabe-se que possuem maiores taxas de cesariana.

No setor privado houve maior percepção de que a cesariana é o parto mais seguro para o bebê, e os principais fatores para justificar essa escolha foram devido às experiências prévias positivas, possibilidade de programar a data do parto e de ter o profissional conhecido presente. Já entre as multíparas do setor público, a principal justificativa para preferência da cesariana foi a realização da laqueadura tubária (DOMINGUES RMSM, et al., 2014).

O discurso de mulheres evidencia que a escolha pelo tipo de parto vai além do que elas desejam, pois depende do recebimento de orientações e informações de qualidade durante o pré-natal e, envolve aspectos familiares e culturais, visto que as opiniões e relatos de vivências de pessoas do convívio da gestante, são um forte fator de influência (OLIVEIRA VJ e PENNA CMM, 2018; ARIK RM, et al., 2019; MARTINS APC, et al., 2018; NASCIMENTO RRP, et al., 2015).

A decisão do profissional de saúde também tem peso significativo na decisão da mulher pela via de parto, principalmente se tratando do médico, o que é preocupante pelo fato de que muitos profissionais ainda repassam informações tendenciosas para a realização de uma cesariana, seja por interesses econômicos, 
como por conveniência. Percebe-se ainda, que no momento do parto, as mulheres que não foram instruídas sobre a fisiologia e o tempo do trabalho de parto, se tornam ainda mais vulneráveis às decisões da equipe (SILVA MMJ, et al., 2019; PAIVA ACPC, et al., 2019; KOTTWITZ F, et al., 2018).

A proximidade com o profissional médico também aparece como influência na escolha da cesárea, pela viabilidade de ter o mesmo médico que as acompanhou durante o pré-natal no momento do parto, visto que o profissional pode se programar para fazer o procedimento, o que nem sempre é possível no parto vaginal (PAIVA ACPC, et al., 2019).

Para Martins APC, et al. (2018), a interferência dos profissionais de saúde não ocorre em sua maioria durante o pré-natal, mas no momento do parto, onde as mulheres aceitam a mudança na opção inicial, movidas pelo medo, insegurança e sua vulnerabilidade no momento, preocupando-se em garantir o bemestar e em não sentir dor, prevalecendo a decisão médica no processo de escolha.

Uma das pesquisas utilizadas, avaliou e comparou os discursos entre mulheres, médicos e enfermeiros, revelando que a decisão pela via de parto, apresenta uma dependência excessiva da determinação do médico. Enquanto o médico justifica ser persuadido a realizar cesariana pela escolha da mulher que não deseja sentir dor, a enfermagem traz no seu discurso, que a mulher escolhe a cesárea com medo de sua dor ser negligenciada ou de ser desrespeitada durante o trabalho de parto. Nota-se que até certo ponto, o desejo da mulher é respeitado, entretanto, a maioria delas não tem claro que podem ter uma atuação mais ativa no processo de escolha pela via de parto e diante do medo, transferem essa responsabilidade para o médico (OLIVEIRA VJ e PENNA CMM, 2018; PEREIRA RR, et al., 2011).

\section{Papel do profissional enfermeiro}

A preparação para o parto deve acontecer desde o pré-natal, e o papel dos profissionais de saúde é de suma importância durante esse processo, visto que suas opiniões influenciam a percepção das gestantes, principalmente acerca da via de parto. Percebe-se o enfermeiro, como um dos principais profissionais que busca incentivar o parto vaginal e o protagonismo da mulher na parturição (VALE LD, et al., 2015; DOMINGUES RMSM, et al., 2014).

Independente da via de parto escolhida, a base para a tomada de decisões da gestante está nas informações recebidas. Nessa perspectiva entra o papel fundamental do enfermeiro, que deve ter uma participação mais ativa no pré-natal e apropriar-se das estratégias de orientação, para prestar uma assistência mais integral e humanizada, preconizando atividades educativas individuais, pautadas na escuta, no diálogo e no aconselhamento, ou em grupo, promovendo momentos de troca de experiências e sentimentos (MARTINS APC, et al., 2018; DEMARCHI RF, et al., 2017).

Para que as mulheres possam exercer a sua autonomia e o direito de escolha, elas precisam receber uma educação em saúde de qualidade durante o pré-natal, tendo esclarecidos os procedimentos a que poderão ser submetidas e seus riscos e benefícios. Os enfermeiros devem buscar o empoderamento das parturientes, e fornecer as orientações necessárias por meio de um diálogo claro e compreensível, além de contribuir para que os desejos das mesmas sejam atendidos (SILVA DES, et al., 2020; PAIVA ACPC, et al., 2019).

Demarchi RF, et al. (2017), traz no seu estudo, o enfermeiro como o principal responsável pelo sucesso do pré-natal, uma vez que ele traz maior atenção ao cuidado gestacional e às queixas e dúvidas da gestante. identificou-se ainda a manifestação do desejo das mulheres de passarem por mais consultas com esse profissional.

Por fim, percebe-se uma necessidade urgente de aprimorar a assistência pré-natal, orientando as gestantes quanto as diferenças das vias de parto, seus riscos e benefícios, sobre as práticas benéficas que podem ser usadas durante o trabalho de parto, para que a mulher possa construir uma opinião acerca da via desejada de forma consciente. Apesar de que em muitos lugares, o enfermeiro ainda tem uma atuação mais tímida, principalmente se tratando de opinar na escolha do tipo de parto, com a sua dinamicidade e capacidade, enxerga-se nele, um importante ator para a melhora dessa assistência, promovendo 0 protagonismo e autonomia da mulher nesse processo (MARTINS APC, et al., 2018; OLIVEIRA VJ e PENNA CMM, 2018; KOTTWITZ F, et al., 2018). 


\section{CONSIDERAÇÕES FINAIS}

Evidenciou-se que o processo de decisão pela via de parto envolve, além das preferências da gestante, também as da família e as dos profissionais de saúde, e que surgem diferentes argumentos para justificar a escolha. Se tratando da preferência pelo parto vaginal, o principal fator citado é a melhor e mais rápida recuperação no pós-parto, já para a realização da cesárea o fator que mais aparece é o medo da dor do parto vaginal. Percebe-se que a autonomia da gestante para a escolha do tipo de parto, está muito relacionada a disponibilidade de informações durante o pré-natal, nesse contexto entra o papel fundamental do enfermeiro, sendo um importante ator no processo educativo das gestantes, devendo ampliar a sua atuação e ter uma participação mais ativa no pré-natal. O presente estudo torna-se importante por reconhecer os motivos da preferência materna por cada tipo de parto, além dos aspectos que influenciam as mudanças na decisão das mesmas, assim possibilitando que seja traçado uma linha de cuidado direcionada a esses fatores.

\section{REFERÊNCIAS}

1. ARIK RM, et al. Percepções e expectativas de gestantes sobre o tipo de parto. Revista Brasileira de Enfermagem, 2019; 72: 46-54.

2. CARVALHO SS, CERQUEIRA RFN. Influência do pré natal na escolha do tipo de parto: revisão de literatura. Revista de Atenção à Saúde, 2020; 18(63): 120-128.

3. DARÓS DZ, et al. Socialização de conhecimentos e experiências sobre o processo de nascimento e tecnologias do cuidado. Revista Eletrônica de Enfermagem, 2010; 12(2): 308-314.

4. DEMARCHI RF, et al. Percepção de gestantes e puérperas primíparas sobre a maternidade. Revista de Enfermagem UFPE online, 2011; 11(7): 2663-2673.

5. DOMINGUES RMSM, et al. Processo de decisão pelo tipo de parto no Brasil: da preferência inicial das mulheres à via de parto final. Caderno de Saúde Pública, 2014; 30: 101-116.

6. FEITOSA RMM, et al. Fatores que influenciam a escolha do tipo de parto na percepção das puérperas. Revista de Pesquisa Cuidado é Fundamental Online, 2017; 9(3): 717-726.

7. FREIRE NC, et al. Parto normal ou cesárea? A decisão na voz das mulheres. Revista Baiana de Enfermagem, 2011; 25(3): 237-247.

8. KOTTWITZ F, et al. Via de parto preferida por puérperas e suas motivações. Escola Anna Nery Revista de Enfermagem, 2018; 22(1):1-8.

9. LEAL MC, et al. Nascer no Brasil - Sumário Executivo Temático da Pesquisa. 2014. Disponível em: http://www.ensp.fiocruz.br/portal-ensp/informe/site/arquivos/anexos/nascerweb.pdf. Acessado em: $17 \mathrm{de}$ abril de 2021.

10. MARTINS APC, et al. Aspectos que influenciam a tomada de decisão da mulher sobre o tipo de parto. Revista Baiana de Enfermagem, 2018; 32: e25025.

11. MATOS GC, et al. Parto normal ou cesárea na adolescência: de quem é a decisão? Revista de Enfermagem UFPE online, 2018; 12(6): 1681-1687.

12. MINISTÉRIO DA SAÚDE. Diretrizes nacionais de assistência ao parto normal. 2017. Disponível em: https://bvsms.saude.gov.br/bvs/publicacoes/diretrizes_nacionais_assistencia_parto_normal.pdf. Acessado em: 21 de abril de 2021.

13. MINISTÉRIO DA SAÚDE. Humanização do parto e do nascimento. 2014 . Disponível em: https://www.redehumanizasus.net/sites/default/files/caderno_humanizasus_v4_humanizacao_parto.pdf. Acessado em: 21 de abril de 2021.

14. NASCIMENTO RRP, et al. Escolha do tipo de parto: fatores relatados por puérperas. Revista Gaúcha de Enfermagem, 2015; 36: 118-126.

15. OLIVEIRA VJ, PENNA CMM. Cada parto é uma história: processo de escolha da via de parto. Revista Brasileira de Enfermagem, 2018; 71: 1304-1312.

16. ORGANIZAÇÃO MUNDIAL DE SAÚDE. Declaração da OMS sobre Taxas de Cesáreas. 2015. Disponível em: http://apps.who.int/iris/bitstream/10665/161442/3/WHO_RHR_15.02_por.pdf?ua=1\&ua=1. Acessado em: 21 de abril de 2021.

17. PAIVA ACPC, et al. Da decisão à vivência da cesariana: a perspectiva da mulher. Revista de enfermagem do CentroOeste Mineiro, 2019; 9: e3115.

18. PEREIRA RR, et al. Representações sociais e decisões das gestantes sobre parturição: protagonismo das mulheres. Saúde e Sociedade, 2011; 20(3): 579-589.

19. RISCADO LC, et al. A decisão pela via de parto no Brasil: temas e tendências na produção da saúde coletiva. Texto Contexto Enfermagem, 2016; 25(1): 1-10.

20. SILVA AKB, et al. Parto normal X Parto cesáreo: escolha ou necessidade? Revista de Enfermagem UFPE Online, 2011; 5(4): 1000-1006.

21. SILVA DES, et al. Razões maternas da preferência inicial pelo tipo de parto em um município do nordeste brasileiro. Revista Cogitare Enfermagem, 2020; 25: e68997.

22. SILVA MMJ, et al. Autonomia da gestante na escolha do tipo de parto. Investigación en Enfermería: Imagen y Desarrollo, 2019; 21(2).

23. VALE LD, et al. Preferência e fatores associados ao tipo de parto entre puérperas de uma maternidade pública. Revista Gaúcha de Enfermagem, 2015; 36(3): 86-92. 